\title{
Ischemia-Guided Percutaneous Revascularization
}

Abbreviations: SCAD: Stable Coronary Artery Disease; PCIs: Percutaneous Coronary Interventions; CABG: Coronary Artery Bypass Graft; MACCE: Major Adverse Cardiac and Cerebrovascular Events; FFR: Fractional Flow Reserve

\section{Opinion}

Revascularization therapy for stable coronary artery disease (SCAD) guided by induction test of ischaemia is one of the principal hot topics in the actual guidelines. The presence and extension of inducible ischemia is one of the most important factors related to bad outcome [1]. In patients with SCAD, a number of studies have analysed the role of ischemia-guided percutaneous revascularization, either by non-invasive or invasive methods. Non-invasive imaging studies with exercise echocardiography suggest that treatment of non ischemic coronary lesions may be safely deferred with an annual estimated incidence of death or MI of $0.6 \%$, as reported in the meta-analysis of Meltz et al. [2]. The study of Hachamovitch et al. [3] emphasized the relationship between inducible ischemia on SPECT and the presence of shortterm survival benefits with early revascularization vs. medical therapy.Revascularization was associated with a reduction in mortality for patients having moderate to severe ischemia. The cut-off level of ischemic myocardium, assessed by summed stress scores, to predict lower mortality using revascularization was approximately $10-12.5 \%$ [3]. Kim et al. [4] supported the benefit of ischemia-guided revascularization with myocardial perfusion imaging for patients with multivessel coronary artery disease. The outcomes of ischemia-guided revascularization were retrospectively compared with those of non ischemiaguided revascularization in a registry of 5,340 patients with multivessel coronary disease comprising 2,587 percutaneous coronary interventions (PCIs) with drug-eluting stents and 2,753 coronary artery bypass graft (CABG) surgeries. The incidence of major adverse cardiac and cerebrovascular events (MACCE) was significantly lower in the ischemia-guided than in the non ischemia-guided group, primarily driven by the lower repeat revascularization rate. Subgroup analysis showed that ischemiaguided reduced the risk of MACCE in PCI but not in CABG patients [4]. Several diagnostic modalities are available for use as tools to establish the initial diagnosis, assess disease severity, and select the appropriate treatment strategy in symptomatic patients suspected of having SCAD. In relation to this point, a multicenter study performed in Japan hypothesise that the choice of the initial diagnostic test might influence the treatment strategy. They showed that patients receiving initial SPECT had a lower rate of revascularization than those receiving coronary angiography [5].

In relation to invasive methods assessing ischemia, fractional flow reserve (FFR) is considered nowadays the elective way for invasive assessment of physiological stenosis significance and a decisive tool for decision making in coronary revascularization. The recently published ESC guidelines on the management of stable coronary artery disease endorse the use of FFR for risk stratification. FFR is calculated as the ratio of distal coronary pressure to aortic pressure measured during maximal hyperaemia.

Opinion
Volume 4 Issue 2 - 2015
Isaac Pascual, César Morís and Pablo
Avanzas*
Cardiac Catheterization Laboratories, Area del Corazón,
Hospital Universitario Central de Asturias, Spain
*Corresponding author: Pablo Avanzas Fernandez, Cardiac
Catheterization Laboratories, Area del Corazón, Hospital
Universitario Central de Asturias, Oviedo, Spain, Email:
avanzas@secardiologia.es
Received: November 30, 2015 | Published: December 01,
2015

A normal value for FFR is 1.0. Stenoses with a FFR $>0.80$ are hardly ever associated with exercise-induced ischaemia [6]. The principal utility of FFR is in certain situations when it is not clear whether an intermediate angiographic lesion causes ischemia. The use of FFR in the catheterization laboratory accurately identifies which lesions should be revascularized and improves the outcome in most elective clinical and angiographic conditions, as compared with the situation where revascularization decisions are simply made on the basis of angiographic appearance of the lesion [7]. The DEFER study evaluated the 5-year outcomes in 325 patients assigned to 3 groups: deferred group (FFR $\geq 0.75$ without PCI), PCI group (FFR $\geq 0.75$ with PCI), and a control group (FFR $<0.75$ with PCI). 5-year event-free survival rates were similar in the deferred and PCI groups, with a risk of cardiac death or MI in patients with normal FFR inferior to 1\% per year [8]. FAME study evaluated angio-guided versus FFR-guided percutaneous revascularization in patients with multivessel disease. Routine measurement of FFR in patients with multivessel coronary artery disease who were undergoing PCI with drug-eluting stents significantly reduced the rate of the composite end point of death, nonfatal myocardial infarction, and repeat revascularization at one year of follow up [9]. The 2-year outcome report of the FAME study supported the safety of deferring PCI for non ischemic lesions [10]. Of interest, a sub analysis of the FAME study also showed that angiography is inaccurate in assessing the functional significance of a coronary stenosis when compared with the FFR in the $50 \%$ to $70 \%$ category but also in the $70 \%$ to $90 \%$ angiographic severity category [11]. The FAME-2 trial tested the benefits, for SCAD, of FFR-guided PCI plus optimal medical therapy with optimal medical treatment alone. PCI group had significant lower rate of primary endpoint event: death, MI, or urgent revascularization. Also there was a lower rate of urgent revascularization in the PCI group than in the medical therapy group [12].

Some nonrandomized observational studies have also shown the benefits of ischemia-guided revascularization. In the post acute coronary syndrome setting, once the culprit lesion has been treated, the severity of different stable lesions can also be assessed 
by FFR. Non-invasive stress testing immediately after the acute phase may be not possible, and furthermore, non-conclusive or contraindicated. In stabilized patients with recent acute coronary syndrome, FFR of non-culprit lesions can be safely evaluated, either during the index procedure or in a staged procedure [13].

The usefulness of FFR-guided revascularization strategy have been consistently demonstrated in different angiographic scenarios like left main, isolated left anterior descending coronary artery, small vessels or bifurcation lesions. Hamilos et al. [14] reported that angiography alone did not allow appropriate individual decision making about the need for revascularization in patients with equivocal stenosis of the left main coronary artery. Moreover, this study supported that angiography often underestimates the functional significance of the stenosis of the left main. The favourable outcome of an FFR-guided strategy suggests that FFR should be assessed in such patients before taking the decision about the need for revascularization [14]. Muller et al. [15] proposed the usefulness of FFR-guiding percutaneous revascularization of isolated proximal left anterior descending coronary artery. This study concluded that the medical treatment of patients with a hemodynamically non significant stenosis (FFR $\geq 0.80$ ) in the proximal LAD was associated with an excellent longterm clinical outcome with survival at 5 years similar to an ageand sex-matched control population [15]. In a study reported by Puymirat et al. [16] FFR-guided percutaneous revascularization of small coronary arteries was safe and resulted in better clinical outcome when compared with an angio-guided PCI [16]. The utility of FFR in percutaneous intervention for bifurcation lesions has been evaluated by Kumsars et al. [17]. The usefulness of FFR in this situation was to identify the functional grade of stenosis of the side branch [17].

All these studies indicate that ischemia guided PCI may reduce the cost, radiation exposure and procedural complications by avoiding unnecessary, complex procedures and consequently improving long-term prognosis. In addition, several studies have suggested that patients with more extensive ischaemia benefit from revascularization therapy, and this benefit could achieve long-term survival benefit if the ischaemia is severe and if significant reduction of ischaemia is achieved. The future directions of this field are focus on the ISCHEMIA (International Study of Comparative Health Effectiveness with Medical and Invasive Approaches) trial.This is a clinical trial that randomizes SIHD patients at a uniformly higher risk prior to cardiac catheterization to determine optimal management for patients with SIHD. This trial will better clarify the benefits of ischemiaguided revascularization for stable CAD patients.

We would like to remark that all patients with SIHD benefit from optimal medical therapy in addition to a healthy lifestyle. Revascularization exerts favourable effects on symptoms, quality of life, exercise capacity, and survival in some cases. The decision to revascularize a patient should be based on the presence of significant obstructive coronary artery stenosis, the amount of related ischaemia and the expected benefit to prognosis. Revascularization can offer survival benefits in highrisk, stable-angina patients, who are formally defined as those with multivessel coronary artery involvement or left main CAD, LVEF dysfunction and extensive ischemia. Stable-angina patients who are low risk on the basis of these criteria should not undergo revascularization procedures unless they experience significant angina, in which case revascularization can improve quality of life.

\section{References}

1. Califf RM, Armstrong PW, Carver JR, D'Agostino RB, Strauss WE (1996) $27^{\text {th }}$ Bethesda Conference: matching the intensity of risk factor management with the hazard for coronary disease events. Task Force 5.Stratification of patients into high, medium and low risk subgroups for purposes of risk factor management. J Am Coll Cardiol 27(5): 1007-1019.

2. Metz LD, Beattie M, Hom R, Redberg RF, Grady D, et al. (2007) The prognostic value of normal exercise myocardial perfusión imaging and exercise echocardiography: A meta-analysis. J Am Coll Cardiol 49(2): 227-237.

3. Hachamovitch R, Hayes SW, Friedman JD, Cohen I, Berman DS (2003) Comparison of the short-term survival benefit associated with revascularization compared with medical therapy in patients with no prior coronary artery disease undergoing stress myocardial perfusion single photon emission computed tomography. Circulation 107(23): 2900-2907.

4. Kim YH, Ahn JM, Park DW, Song HG, Lee JY, et al. (2012) Impact of ischemia-guided revascularization with myocardial perfusión imaging for patients with multivessel coronary disease. J Am Coll Cardiol 60(3): 181-190.

5. Yamauchi T, Tamaki N, Kasanuki H, Kimura T, Uemura Y, et al. (2012) Optimal initial diagnostic strategies for the evaluation of stable angina patients: A multicenter, prospective study on myocardial perfusión imaging, computed tomographic angiography, and coronary angiography. Circ J 76(12): 2832-2839.

6. Pijls NH, Sels JW (2012) Functional measurement of coronary stenosis. J Am CollCardiol 59(12): 1045-1057.

7. Wijns W, Kolh P, Danchin N, Di Mario C, Falk V, et al. (2010) Guidelines on myocardial revascularization. Eur Heart J 31(20): 2501-2555.

8. Pijls NH, van Schaardenburgh P, Manoharan G, Boersma E, Bech JW, et al. (2007) Percutaneous coronary intervention of functionally nonsignificant stenosis: 5-year follow-up of the DEFER Study. J Am Coll Cardiol 49(21): 2105-2111.

9. Tonino PA, De Bruyne B, Pijls NH, Siebert U, Ikeno F, et al. (2009) FAME Study Investigators.Fractional flow reserve versus angiography for guiding percutaneous coronary intervention. N Engl J Med 360(3): 213-224.

10. Pijls NHJ, Fearon WF, Tonino PA, Siebert U, Ikeno F, et al. (2010) Fractional flow reserve versus angiography for guiding percutaneous coronary intervention in patients with multivessel coronary artery disease: 2-year follow-up of the FAME (Fractional Flow Reserve Versus Angiography for Multivessel Evaluation) Study. J Am Coll Cardiol 56(3): 177-184.

11. Tonino PA, Fearon WF, De Bruyne B, Oldroyd KG, Leesar MA, et al. (2010) Angiographic versus functional severity of coronary artery stenoses in the FAME study fractional flow reserve versus angiography in multivessel evaluation. J Am Coll Cardiol 55(25): 2816-2821.

12. De Bruyne B, Pijls NH, Kalesan B, Barbato E, Tonino PA, et al. (2012) FAME 2 Trial Investigators. Fractional flow reserve-guided $\mathrm{PCI}$ versus medical therapy in stable coronary disease. N Engl J Med 367(11): 991-1001. 
13. Ntalianis A, Sels JW, Davidavicius G, Tanaka N, Muller O, et al. (2010) Fractional flow reserve for the assessment of nonculprit coronary artery stenoses in patients with acute myocardial infarction.JACC CardiovascInterv 3(12): 1274-1281.

14. Hamilos M, Muller O, Cuisset T, Ntalianis A, Chlouverakis G, et al (2009) Long-term clinical outcome after fractional flow reserveguided treatment in patients with angiographically equivocal left main coronary artery stenosis. Circulation 120(15): 1505-1512.

15. Muller O, Mangiacapra F, Ntalianis A, Verhamme KM, Trana C, et al (2011) Long-term follow-up after fractional flow reserve-guided treatment strategy in patients with an isolated proximal left anterior descending coronary artery stenosis. JACC CardiovascInterv 4(11): 1175-1182.

16. Puymirat E, Peace A, Mangiacapra F, Conte M, Ntarladimas Y, et al. (2012) Long-term clinical outcome after fractional flow reserveguided percutaneous coronary revascularization in patients with small-vessel disease. Circ CardiovascInterv 5(1): 62-68.

17. Kumsars I, Narbute I, Thuesen L, Niemelä M, Steigen TK, et al. (2012) Side branch fractional flow reserve measurements after main vessel stenting: a Nordic-Baltic Bifurcation Study III substudy. EuroIntervention 7(10): 1155-1161. 